\title{
Salvage CryoBalloon cryotherapy ablation for a duodenal adenoma
}

A 73-year-old man was referred for therapy of a duodenal adenoma discovered incidentally for an esophagogastroduodenoscopy (EGD) performed for evaluation of gastroesophageal reflux disease. On EGD the polyp ( $\triangleright$ Fig. 1) measured $3 \mathrm{~cm}$ and was sessile and slightly elevated (Paris classification 0-Ila). Preparations were made for endoscopic mucosal resection (EMR). A solution of $3 \%$ hetastarch, normal saline, and methylene blue was injected into the submucosal layer of the distal aspect of the polyp. The distal aspect of the polyp lifted well. An attempt was made to lift the central and proximal component of the polyp, but the lift was not adequate to allow EMR. Attempts were made using a waterjet probe (Erbejet 2; Erbe USA, Marietta, GA, USA) at high settings of $360 \mathrm{psi}$ (Effect 25) and then 725 psi (Effect 50). Given the lack of lifting after submucosal injection, the decision was made to perform cryotherapy using the CryoBalloon
(C2 CryoBalloon Focal Ablation System; Pentax Medical, Redwood City, CA, USA). This had been discussed with the patient prior to the procedure as a backup option. Two 10-second ablations were applied to the polyp ( $\mathbf{F i g . 2}$ ). A deep erythema of the polyp was seen, indicating effective ablation. The polyp was biopsied extensively using a jumbo biopsy forceps, and the pathological study showed low-grade dysplasia (histology immediately after cryotherapy is not affected by the cryotherapy, the effects of which occur later). The patient returned 3 months after the procedure for follow-up. At this point about $30 \%$ of the polyp remained ( $\mathbf{F i g . 3}$ ). Another CryoBalloon ablation treatment was applied, this time with a single 10 -s ablation. Biopsies again showed low-grade dysplasia. At 6-month follow-up no polyp remained. Biopsy of the scar showed benign tissue (> Fig. 4 ).

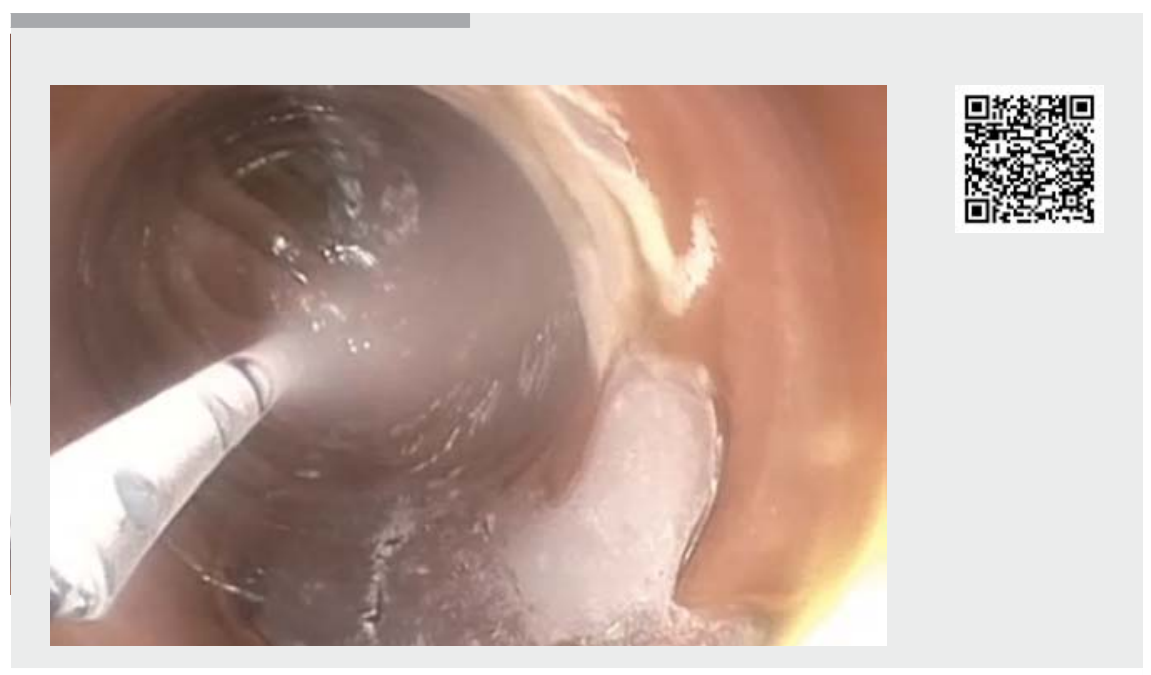

Video 1 Salvage CryoBalloon ablation of a duodenal polyp after it could not be removed by endoscopic mucosal resection technique due to failure to lift with a submucosal injection.

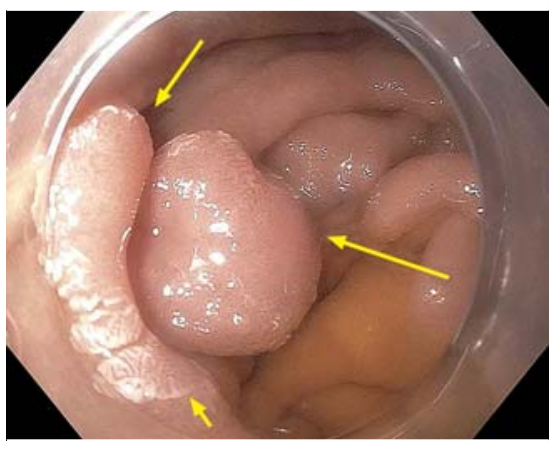

- Fig. 1 Duodenal polyp before submucosal injection (arrows).

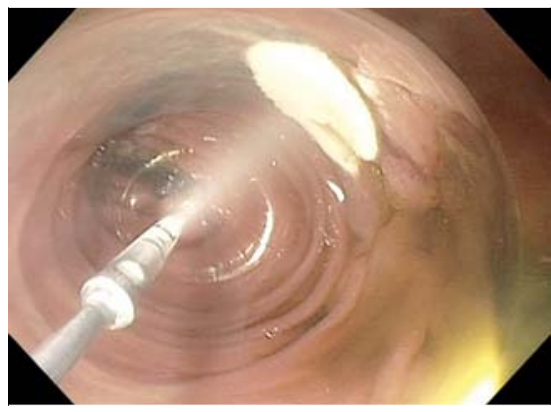

- Fig. 2 CryoBalloon cryotherapy ablation of the duodenal polyp after unsuccessful submucosal injection of the whole polyp.

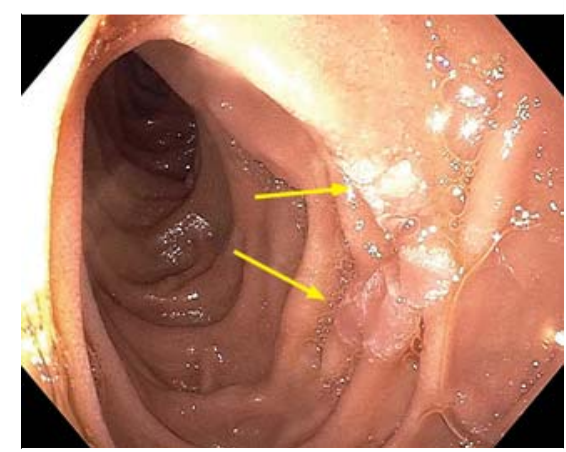

Fig. 3 Duodenal polyp (arrows) at 3-month follow-up after the first CryoBalloon ablation session: $30 \%$ of the polyp remains. 


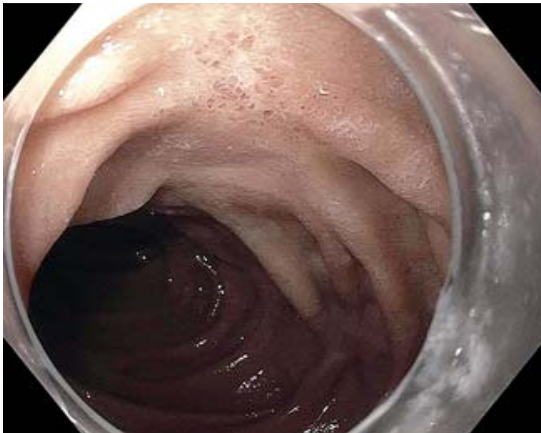

Fig.4 Duodenum at the site of the CryoBalloon ablation at 6-month followup: no duodenal polyp remains.

This case shows that CryoBalloon cryotherapy can be an effective option for eradication of duodenal polyps when EMR cannot be performed.

Endoscopy_UCTN_Code_CPL_1AH_2AZ
A. J.T. is a consultant to Pentax Medical. All other authors have no conflict of interest to report.

The authors

Kara L. Raphael, Petros C. Benias, Arvind J. Trindade

Division of Gastroenterology, Long Island Jewish Medical Center, Zucker School of Medicine at Hofstra/Northwell, Northwell Health System, New Hyde Park, NY, USA

\section{Corresponding author}

\section{Arvind J. Trindade}

Division of Gastroenterology, Long Island Jewish Medical Center, Zucker School of Medicine at Hofstra/Northwell, Northwell Health System, 270-05 76th Avenue, New Hyde Park, NY 11040, USA

Fax: +1-718-470-5509

arvind.trindade@gmail.com

\section{Bibliography}

DOI https://doi.org/10.1055/a-1066-4518

Published online: 9.12.2019

Endoscopy 2020; 52: E189-E190

(c) Georg Thieme Verlag KG

Stuttgart · New York

ISSN 0013-726X

\section{ENDOSCOPY E-VIDEOS}

https://eref.thieme.de/e-videos

回回 Endoscopy E-Videos is a free access online section, reporting on interesting cases and new

techniques in gastroenterological endoscopy. All papers include a high quality video and all contributions are freely accessible online.

This section has its own submission website at

https://mc.manuscriptcentral.com/e-videos 